Lösung von Kaliumkadmiumjodid gefällt, Gegen Allantoin, Alloxan, Oystin, Guanin, Harnstoff, Kreatin, Kreatinin, Leucin, Taurin, Xanthin verhält sich jedoch das genannte Reagens, ebenso wie eine Lösung von Jodkadmium, indifferent. Auch auf die Glucoside, Amygdalin, Salicin, Phloridzin, Aesculin, Saponin, Cyclamin, Ononin, Digitalin, Glycyrrhizin, Colocynthin, Helleboreïn, Helleborin wirkt das Reagens nicht, ebensowenig auf Asparagin und endlich auch nicht auf fixes und fittchtiges Alkali in angesäuerter Lösung. - Die Niederschläge der Alkaloïde sind zunächst alle flockig und weiss, werden aber zum Theil sehr bald krystallinisch. Morphin wird aus stärkeren Lösungen gallertartig, aus verdünnteren in relativ grossen federigen Krystallen gefällt - Chinin und Strychnin werden bei 10000 facher Verdünnung. flockig und vollständig gefällt. - Die Niederschläge sind unlöslich in Aether, leicht löslich in Alkohol, weniger in Wasser, leicht in einem Ueberschuss des Fällungsmittels. Sie zersetzen sich zum Theil beim längeren Stehen ebenso wie die entsprechenden Jodquecksilber - und Jodwismuth-Alkaloïdverbindungen von $\mathrm{Pl}$ ant a und $\mathrm{Dr}$ agend orff. Aus den Niederschlägen lassen sich die Alkaloïde wiedergewinnen durch Uebersättigen der Lösung mit einem entsprechenden Alkali und nachfolgendem Schütteln mit einem geeigneten Lösungsmittel; Benzin z. B. nach Rodgers für Strychnil und nach D ragendorff auch für viele andere Alkaloïde. - Das Reagens, dargestellt durch Eintragen von Jodkadmium in eine concentrirte kochende Lösung von Jodkalium bis zur Sättigung und Zusatz eines gleichen Volumens kalt gesättigter Jodkaliumlösung, hält sich lange Zeit unzer'setzt, verdünnte Lösungen sind nicht haltbar.

Prüfung des schwefelsauren Chinins. Zur Prüfung, des Chinins auf Chinidin etc. empfiehlt Stoddart*) folgende Methoden: In ein verschliessbares Glasrohr bringt man $0,6 \mathrm{Grm}$, des verdächtigen Salzes, löst in 0,5 Grm. Schwefelsäure, die man mit $3 \mathrm{Grm}$. Wasser verdünnt hat, und versetzt die erhaltene Lösung mit 7,5 Grm. Aether, $0,18 \mathrm{Grm}$. Alkohol und $2 \mathrm{Grm}$. einer Natronlauge von circa 8 Proc. Nảch gründlichem Umschütteln überlässt man 12 Stunden der Ruhe. Ist Chinidin, Cinchonin oder Cinchonidin vorhanden, so finden sie sich an der Trennungsfläche des Aethers vereinigt, das Chinidin in der Form einer öligen Schicht, das Cinchonidin dagegen krystallinisch. Die zweite Methode besteht in der mikroskopischen Untersuchung des krystalli-

*) Journ de pharm. et de chim. Bd. 4, p. 50. 
nischen Niederschlags, welchen eine I,ösung von Schwefelcyankalium (10 Grm, in 45 Grm. Wasser) in einer gesättigten und neutralen Lösung des zu prïfenden Chininsulfats erzeugt.

\section{Uebersicht des Verhaltens der medicinischen flïchtigen Basen gegen die wichtigsten Reagentien *).}

W bedeutet wässerige Lösung; S bedeutet Salz-oder saure Lösung.

\begin{tabular}{|c|c|c|c|}
\hline Reagentien. & Ammoniak. & Trimethylamin. & Anilin \\
\hline Kalinmbijodid. & $\begin{array}{l}\text { W. Entfärbung. } \\
\text { S. Keine Verände- } \\
\text { rung.' }\end{array}$ & $\begin{array}{c}\text { W u. S. Orangegel- } \\
\text { ber Niederschlag. }\end{array}$ & $\begin{array}{l}\text { Braune Lösung, spä- } \\
\text { ter Niederschlag } \\
\text { oder nicht. }\end{array}$ \\
\hline Gerbsäure. & $\begin{array}{l}\text { W. KeinNiederschlag. } \\
\text { S. Niederschlag von } \\
\text { Gerbsäure, wenn } \\
\text { concentrirt. }\end{array}$ & $\begin{array}{l}\text { In neutralen und al- } \\
\text { kalischen Lösungen } \\
\text { weisser käsigerNie- } \\
\text { derschlag. }\end{array}$ & Kein Niederschlag. \\
\hline Sublimat. & $\begin{array}{l}\text { W. Weisser Nieder- } \\
\text { schlag. }\end{array}$ & $\begin{array}{l}\text { W. Weisser Nieder- } \\
\text { schlag. }\end{array}$ & Kein Niederschlag. \\
\hline $\begin{array}{l}\text { Kalium - Queck- } \\
\text { silberjodid. }\end{array}$ & $\begin{array}{l}\text { S. Kein Niederschlag; } \\
\text { mit Kalilauge } \\
\text { orangebrauner Nie- } \\
\text { derschlag. } \\
\text { W. Weissgelber, im } \\
\text { Ueberschuss lösli- } \\
\text { cher Niederschlag. }\end{array}$ & $\begin{array}{l}\text { S. Eine lockere Masse } \\
\text { von blassgelben } \\
\text { Krystallen; leicht } \\
\text { löslich in Jodka- } \\
\text { lium und in Kali- } \\
\text { lauge; durch Schüt- } \\
\text { teln mit Wasser } \\
\text { zersetzbar } \\
\text { W. Im Ueberschuss } \\
\text { löslicher Nieder- } \\
\text { schlag. }\end{array}$ & $\begin{array}{l}\text { W. Weisser Nieder- } \\
\text { schlag, löslich in } \\
\text { Ueberschuss und in } \\
\text { Jodkalium; durch } \\
\text { Kalilauge wird er } \\
\text { hervorgebracht, } \\
\text { aber im Ueber- } \\
\text { schuss derselben } \\
\text { wieder löslich. }\end{array}$ \\
\hline $\begin{array}{l}\text { Essigsanres } \\
\text { Bleioxyd. }\end{array}$ & $\begin{array}{l}\text { W. Weisser Nieder- } \\
\text { schlag. }\end{array}$ & $\begin{array}{l}\text { W. Weisser Nieder- } \\
\text { schlag. }\end{array}$ & 0 \\
\hline $\begin{array}{l}\text { Salpetersaures } \\
\text { Silberoxyd. }\end{array}$ & $\begin{array}{l}\text { W. Bräunlicher Nie- } \\
\text { derschlag. }\end{array}$ & $\begin{array}{l}\text { W. Gräulicher, in } \\
\text { Salpetersäure lös- } \\
\text { licherNiederschlag. }\end{array}$ & Kein Niederschlag. \\
\hline Goldchlorid. & $\begin{array}{l}\text { W. Röthlich gelber } \\
\text { Niederschlag. }\end{array}$ & $\begin{array}{l}\text { W. Granlich gelber } \\
\text { Niederschlag, lös- } \\
\text { lich in Salzsäure. }\end{array}$ & W. KeinNiederschlag. \\
\hline Platinchlorid. & 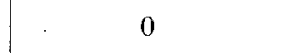 & 0 & 0 \\
\hline $\begin{array}{l}\text { Dichtigkeit } u . \\
\text { Löslichkeit in } \\
\text { Wasser. }\end{array}$ & $\begin{array}{c}\text { Sehr löslich, mit } \\
\text { Wasser mischbar. }\end{array}$ & $\begin{array}{l}\text { Sehr löslich, mit Was- } \\
\text { ser mischbar. }\end{array}$ & $\begin{array}{l}\text { Kaum löslich, } \\
\text { schwimmt auf dem } \\
\text { Wasser. }\end{array}$ \\
\hline
\end{tabular}

*) Pharm. Centralballe. Bd. 7, p. 285. 